Tropical Journal of Pharmaceutical Research August 2020; 19 (8): 1723-1730

ISSN: $1596-5996$ (print); 1596-9827 (electronic) (C) Pharmacotherapy Group, Faculty of Pharmacy, University of Benin, Benin City, 300001 Nigeria.

\title{
In silico screening of potentially bioactive-anti-functional dyspepsia constituents of Magnoliae officinalis Cortex based on molecular docking and network pharmacology
}

\author{
Jun $\mathrm{He}^{1}$, Longjing Wang${ }^{1}$, Guanghua Lv¹, Yingfang Wei ${ }^{1}$, Meng Yang ${ }^{1}$, Yusha \\ Bai $^{1}$, Yunbin Jiang ${ }^{2}$, Fei Long ${ }^{1 *}$ \\ ${ }^{1}$ School of Pharmacy, Chengdu University of Traditional Chinese Medicine, Chengdu $610075,{ }^{2}$ College of Pharmaceutical \\ Sciences and Chinese Medicine, Southwest University, Chongqing 400715, PR China
}

*For correspondence: Email: longfei@cdutcm.edu.cn Tel: +86-18982130823

Sent for review: 28 January 2020

Revised accepted: 22 July 2020

\begin{abstract}
Purpose: To screen for bioactive anti-functional dyspepsia compounds from Magnoliae officinalis Cortex (Hou Po) and to identify the mechanism(s) of action involved.

Methods: The compounds of Hou Po were collected from the literature. The related target proteins were identified from DrugBank. Through "Libdock" module of Discovery Studio 3.5, the compounds were matched with related target proteins. Taking the Libdock score of the original ligand with target protein as standard, components with higher scores than this standard were considered as potential bioactive compounds. Based on Cytoscape software, the interaction networks of the bioactive compound-target protein complexes were mapped. On the other hand, the online DAVID database was used to analyze the GO enrichment and KEGG pathway of each target.

Results: A total of 199 chemical constituents and 13 correlated target proteins were obtained. One hundred and thirty-nine (139) potential bioactive constituents were acquired based on molecular docking. Thirty-one (31) bioactive compounds were selected based on degree values in network analysis. "Palmitone" and "magnolignan $G$ " which had the highest degree values were considered promising and leading compounds. The result of gene enrichment analysis showed that the bioactive compounds exerted their effects mainly via "neuroactive ligand-receptor interaction" pathway and "Cholinergic synapse" pathways.

Conclusion: Based on molecular docking and network pharmacology technique, the material basis for the use of Hou Po in the treatment of FD has been revealed. This finding provides a useful guide in the development of Hou Po-based anti-FD drugs.
\end{abstract}

Keywords: Magnolia officinalis, Hou Po, Molecular docking, Functional dyspepsia, Network pharmacology

This is an Open Access article that uses a fund-ing model which does not charge readers or their institutions for access and distributed under the terms of the Creative Commons Attribution License (http://creativecommons.org/licenses/by/4.0) and the Budapest Open Access Initiative (http://www.budapestopenaccessinitiative.org/read), which permit unrestricted use, distribution, and reproduction in any medium, provided the original work is properly credited.

Tropical Journal of Pharmaceutical Research is indexed by Science Citation Index (SciSearch), Scopus, International Pharmaceutical Abstract, Chemical Abstracts, Embase, Index Copernicus, EBSCO, African Index Medicus, JournalSeek, Journal Citation Reports/Science Edition, Directory of Open Access Journals (DOAJ), African Journal Online, Bioline International, Open-J-Gate and Pharmacy Abstracts

\section{INTRODUCTION}

Hou Po, classified under "resolving dampness with aromatics" in Chinese herbal medicine, is derived from the dried bark of the dried bark of Magnolia officinalis Rehd. et Wils. or Magnolia officinalis Rehd. et Wils. var. biloba Rehd. et Wils. The use of $\mathrm{Hou} \mathrm{Po}$ in China has a long 
history. It was first recorded in "Shen Nong's herbal Classic" 2000 years ago. The ancient book recorded that $\mathrm{Hou} \mathrm{PO}$ has the effect of treating abdominal pain and distension, as well as nausea and vomiting.

Traditional Chinese medicine prescriptions containing Hou Po have good therapeutic effects on diseases of the digestive system in clinics. Ban Xia-Hou Po decoction on functional dyspepsia (FD) patients showed that it effectively reduced abdominal bloating [1]. In addition, results from systems pharmacology analysis on Huo-Xiang-Zheng-Qi decoction revealed the mechanism involved in its therapeutic effect on gastrointestinal diseases [2]. Modern pharmacological have revealed that Hou Po has extensive pharmacological effects, including relief of abdominal distension, as well as antistress, anti-anxiety, anti-depressant, antiinflammatory, and anti-oxidant properties [3, 4]. At present, Hou Po is still widely used in Asian countries [5].

There has been a significant decline in the rate of transformation of novel phytochemicals from traditional Chinese medicine (TCM) to effective drugs, due to the high cost, long cycles, and complicated procedures involved. Interestingly, molecular docking, an advancement in, computer technology, has enhanced the study of bioactive components of TCM. Molecular docking is a computer-based technique for identifying the binding abilities of candidate compounds to target proteins with known structures [6]. Nowadays, increasing research has shown that molecular docking is a good strategy for the discovery and development of drugs from candidate compounds [7]. In general, molecular docking is combined with network pharmacology. The network pharmacology technology was introduced by Hopkins firstly, who used it to screen potential bioactive compounds and reveal the mechanism of action of multiple-component drugs [8].

Although clinical trials have shown that $\mathrm{Hou} P \mathrm{Po}$ is effective against FD, the mechanism of action of the drug is unknown. In the present study, molecular docking was successfully used to screen potentially bioactive anti-FD compounds from Hou Po. Based on results of molecular docking, network pharmacology was performed to screen the key potentially active compounds and to preliminarily reveal the mechanism underlying of its anti-FD effect.

\section{METHODS}

\section{Building of chemical component database}

Chemical compounds from $\mathrm{Hou} P \mathrm{Po}$ were obtained from the literature via CNKI.net (https://www.cnki.net/) and PubMed (https://pubmed.ncbi.nlm.nih.gov/) [4,9]. The chemical structures of the compounds were searched from SciFinder (http://sso.cas.org) or Chemical Book (http://www.chemicalbook.com), while their two-dimensional (2D) structures were sketched using Chem Sketch (version12.0), and saved as "mol" format.

\section{Target fishing}

First, the phrase, "Functional Dyspepsia", was searched in DrugBank database (https://www. drugbank.ca/) to obtain the target proteins. Then, the 3D structures of the target proteins were acquired from RCSB Protein Data Bank (PDB, http://www.pdb.org/). Finally, the available target proteins were screened according to "Homo sapiens" setting, along with the crystal structures with ligands.

\section{Molecular docking}

\section{Active site preparation}

Based on Accelrys Discovery Studio 3.5 (DS 3.5), LibDock was used to carry out highthroughput screening. Each target protein was prepared through removal of water, addition of polar hydrogen, supplementation of incomplete amino acid residues, cleaning of protein, and removal of the poly-conformation [10]. Residues around the original ligands in the crystal structure were selected as the active site of protein and defined as a sphere. The radii of spheres were set at $5 \AA$. Then, original ligands in the sphere were removed. The active amino acid residues were set as a pocket. Other parameters were set as default [11].

\section{Ligand preparation}

The compounds were imported and the protocol "Prepare Ligands" was used to remove duplicates and enumerate isomers or tautomer of all compounds. The ligands were generated in their three-dimensional (3D) forms.

\section{Docking}

The LibDock module was used for docking the prepared target proteins and prepared ligands with default parameter. LibDock score was used to the evaluate affinity of binding of the 
compounds (ligands) to the proteins. Taking the Libdock score of the original ligand with target protein as standard, components with higher scores than this standard were considered as potentially bioactive compounds.

\section{Construction of ligand-target network and screening bioactive compounds}

Based on results of molecular docking, visual networks showing correlation of compounds with target proteins were established using Cytoscape software (3.7.2). The "degree" value in the network represented the numbers of compounds docking with the target proteins. The higher the "degree" values, the larger the shape. Constituents with degree value greater than or equal to 6 are regarded as bioactive compounds.

\section{Target gene analysis}

To illustrate the potential biological effects of target proteins, Gene Ontology (GO) attached to the DAVID was used to achieve gene enrichment. The GO database describes three aspects of the gene of target proteins: molecular function (MF), biological process (BP), cellular components (CC). The parameters were set with count $\geq 3$ and $p$-value $\leq 0.001[12]$. Besides, Kyoto Encyclopedia of Gene and Genomes database (KEGG) was employed for screening for pathways that met the criterion of count $\geq 2$ and $p$-value $\leq 0.001$.

\section{RESULTS}

\section{Chemical component database and target proteins information}

The compound database consisted of 199 compounds (C1-C199) comprising 82 lignans, 40 glycosides (phenylethanoid and phenolic glycosides), 26 alkaloids, 15 volatile oils, 6 flavonoids, and 30 others. 13 target proteins, involved dopamine receptors, serotonin receptors, acetylcholine receptors, and related enzymes, were obtained from the DrugBank database. Details of the 13 target proteins are shown in Table 1.

\section{Molecular docking results}

A total of 139 potentially bioactive compounds were obtained via DS 3.5 using the "LibDock" module. When a compound docked to the target protein, the interaction between the compound and amino acid residues generated hydrogen bonding and conjugation effects. The binding modes of some bioactive compounds with high LibDock scores are shown in Figure 1.
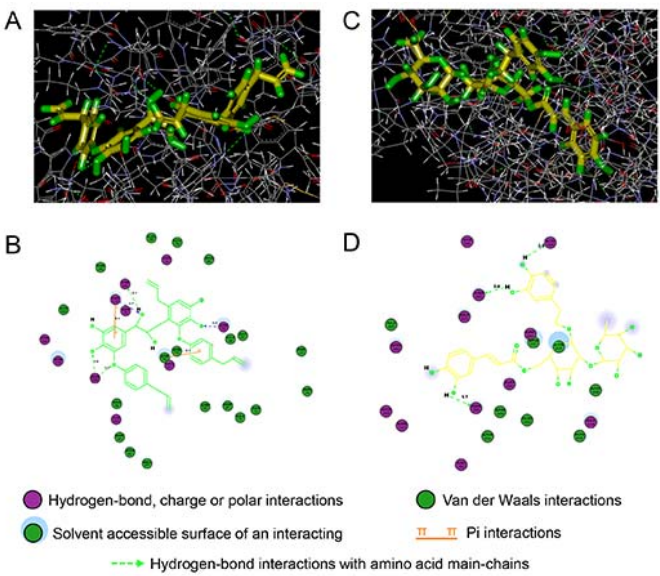

Figure 1: $2 D$ and $3 D$ ligand-protein interaction of high score compounds: (A-B) "magnolignan G" with "Calcitonin gene related peptide receptor" (PDB ID: 3N7R); (C-D) "magnoloside G" with "serotonin $5-\mathrm{HT}_{2 \mathrm{~B}}$ " (PDB ID: 5TVN)

Table 1: Information about 13 target proteins

\begin{tabular}{|c|c|c|c|c|}
\hline No. & PDB ID & Target & Abbreviation & Gene ID \\
\hline 1 & $6 \mathrm{CM} 4$ & Dopamine $\mathrm{D}_{2}$ & DRD2 & 1813 \\
\hline 2 & 3PBL & Dopamine $\mathrm{D}_{3}$ & DRD3 & 1814 \\
\hline 3 & $5 \mathrm{CXV}$ & $\mathrm{M}_{1}$ muscarinic acetylcholine receptor & CHRM1 & 1128 \\
\hline 4 & $3 U O N$ & $\mathrm{M}_{2}$ muscarinic acetylcholine receptor & CHRM2 & 1129 \\
\hline 5 & $5 \mathrm{DSG}$ & $\mathrm{M}_{4}$ muscarinic acetylcholine receptor & CHRM4 & 1132 \\
\hline 6 & $5 T V N$ & Serotonin $5-\mathrm{HT}_{2 B}$ & HTR2B & 3357 \\
\hline 7 & 4DJH & Human kappa opioid receptor & OPRK1 & 4986 \\
\hline 8 & 4IAR & Serotonin 5-HT1B & HTR1B & 3351 \\
\hline 9 & $3 N 7 R$ & Calcitonin gene related peptide receptor & CALCRL & 10203 \\
\hline 10 & 4BDT & Phosphodiesterase 4 & $\mathrm{ACHE}$ & 43 \\
\hline 11 & $4 \mathrm{~A} 79$ & monoamine oxidase & MAOB & 4129 \\
\hline 12 & $4 \mathrm{~K} 5 \mathrm{Y}$ & Corticotrophin-releasing factor 1 & CRHR1 & 1394 \\
\hline 13 & $305 X$ & Tyrosine phosphatase & PTPN11 & 5781 \\
\hline
\end{tabular}




\section{Compound-target network and bioactive compounds}

The network was constructed using 139 potentially bioactive compounds and 13 target proteins are shown in Figure 2. Compounds with degrees greater than or equal to 6 are listed in Table 2, along with their LibDock scores. "Palmitone" and "magnolignan G" had the highest degree value (degree value $=8$ ). Finally, a total of 31 key bioactive compounds were selected through virtual screening and network pharmacology.

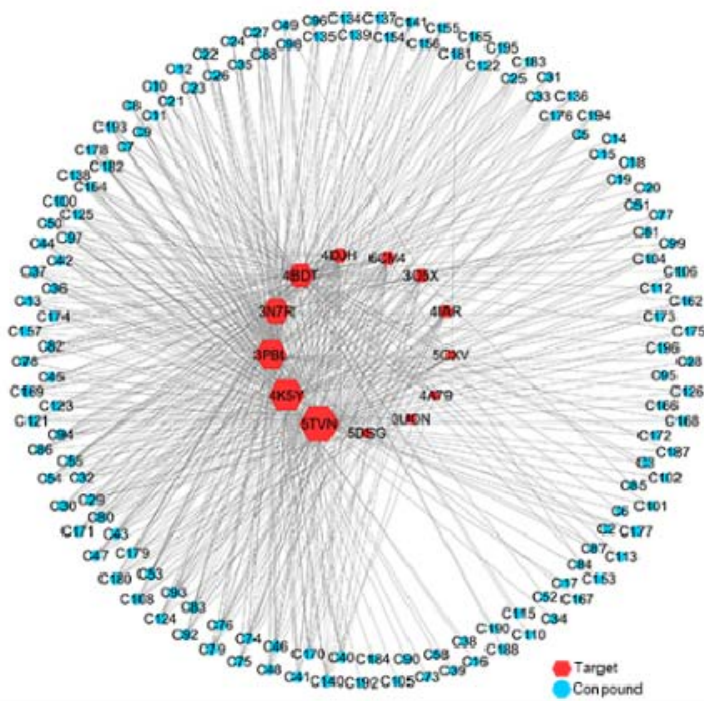

Figure 2: The "compound-target" network of $\mathrm{Hou}$ PO

\section{Gene enrichment analysis}

Gene Ontology (GO) was used to describe the genes in three aspects: molecular function, biological process, and cellular components. The results showed that these genes were enriched to 15 biological process terms, including "Gprotein coupled receptor internalization, adenylate cyclase-inhibiting G-protein coupled acetylcholine receptor signaling pathway". Cellular components described the genes involved in "integral components of plasma membranes, synapse", etc. The biological functions of the genes were described in terms of "molecular transducer activity" and "signal transducer activity" (Figure 3 ). The results of KEGG pathway enrichment analysis with KEGG suggested that 8 pathways were significantly signaling $(p<0.1)$. The "neuroactive ligandreceptor interaction" pathway, "dopaminergic synapse" pathway, and "serotonergic synapse" pathway were obtained (Figure 4).

\section{DISCUSSION}

FD, a type of gastrointestinal disorder, is characterized by the presence of symptoms thought to originate in the gastroduodenal region, in the absence of any organic, systemic, or metabolic disease [13]. A review has shown that FD significantly impacts both the Eastern and the Western countries, with overall higher incidence $(10-40 \%)$ in Western countries than in Asia (5 $30 \%$ ) [14]. The disease has negative impact on the life of patients. Many FD patients usually suffer from abdominal discomfort, pain, burning, early satiety, and bloating [15]. These discomforts could be relieved by promoting gastric motility, reducing gastrointestinal sensitivity, treating gastroduodenal inflammation, regulating emotions, and using appropriate diet. However, enhancement gastrointestinal motility is the main treatment strategy for FD. Unfortunately, with time, the use of drugs that enhance promoting gastrointestinal motility leads to undesirable side effects. Some of these drugs e.g. domperidone, have been banned in the USA, Canada, and other counties [16-20]. Thus, it is crucial to identify novel candidate drugs for treating FD.

In this manuscript, "palmitone" and "magnolignan G" were identified as bioactive components with high degree value. However, there is no direct evidence on the treatment of FD with "palmitone" and "magnolignan G". Interestingly, it has been reported that "palmitone" had a good effect on anxiety and depression [21]. Emotion is one of the causes of FD. Therefore, "palmitone" may be used to treat FD patients through regulation emotions.

The results of this study suggest that attention should be paid to "palmitone" and "magnolignan G". It has been reported that phenylethanoid glycosides in $\mathrm{Hou} P \mathrm{PO}$ contribute significantly to the treatment of FD. "Mmagnoloside A" (degree value $=7$ ), one of the phenylglycoside glycosides, has a positive effect on abdominal distention, pain, and dyspepsia [22]. A literature report indicated that "quercitrin" (degree value = 6 ) regulated gastrointestinal smooth muscle [23].

In this study, the results from molecular docking and network pharmacology, suggest that the bioactive components of $\mathrm{Hou}$ PO exert anti-FD effect by regulating "serotonin $5-\mathrm{HT}_{2 \mathrm{~B}}$ receptor" (PDB ID: 5TVN), "corticotrophin-releasing factor 1 receptor" (PDB ID: 4K5Y), "dopamine $\mathrm{D}_{3}$ receptor" (PDB ID: 3PBL), "calcitonin generelated peptide receptor" (PDB ID: 3N7R), and "Phosphodiesterase 4" (PDB ID: 4BDT). Furthermore, another pathway likely to be 
Table 2: Degree and Libdock scores of 31 bioactive compounds from Hou Po

\begin{tabular}{|c|c|c|c|c|c|c|c|c|c|c|c|c|c|c|c|}
\hline NO. & Compound & $\begin{array}{c}6 \mathrm{CM} \\
4\end{array}$ & 3PB & $5 \mathrm{CXV}$ & $\begin{array}{c}3 U O \\
N\end{array}$ & $\begin{array}{l}\text { 5DS } \\
\text { G }\end{array}$ & $5 T V N$ & $\begin{array}{c}\text { 4DJ } \\
\text { H }\end{array}$ & 4IAR & $\begin{array}{c}\text { 3N7 } \\
\text { R }\end{array}$ & $\begin{array}{l}\text { 4BD } \\
\mathrm{T}\end{array}$ & $\begin{array}{c}\text { 4A7 } \\
9\end{array}$ & $\begin{array}{c}4 K 5 \\
Y\end{array}$ & $\begin{array}{c}305 \\
\times\end{array}$ & $\begin{array}{c}\text { Degre } \\
\text { e }\end{array}$ \\
\hline C140 & Palmitone & 152 & 121 & & & & 161 & 149 & & 180 & & 184 & 112 & 136 & 8 \\
\hline C40 & Magnolignan G & 172 & 127 & & & & 154 & 156 & 164 & 184 & & & 137 & 138 & 8 \\
\hline C180 & $\begin{array}{l}\text { 3,4,5-trimethoxyphenol } \beta \text {-D-apiofuranosyl ( } 1 \\
\rightarrow 6)-\beta \text {-D-glucopyranoside }\end{array}$ & & 109 & 153 & & 157 & 132 & & & 158 & 154 & & 116 & & 7 \\
\hline C179 & $\begin{array}{l}\text { 3,4-dimethoxyphenol } \beta \text {-D-apiofuranosyl (1 } \\
\rightarrow 6)-\beta \text {-D-glucopyranoside }\end{array}$ & & 118 & 166 & 155 & & 136 & & & 166 & 158 & & 129 & & 7 \\
\hline C170 & Pinoresinol-4-O- $\beta$-D-glucopyranoside & & 140 & & & & 162 & 170 & 163 & 187 & & & 122 & 137 & 7 \\
\hline C124 & Choerospondin & 159 & 138 & & & & 153 & 154 & & 177 & & 173 & 168 & & 7 \\
\hline C108 & Magnofficine & & 115 & 150 & & 151 & 132 & & & 154 & 153 & & 149 & & 7 \\
\hline C93 & Magnoloside $Y$ & 169 & 152 & & & & 189 & 165 & 174 & 204 & & & & 144 & 7 \\
\hline C92 & Magnoloside W & 176 & 133 & & & & 164 & 171 & 182 & 201 & & & & 149 & 7 \\
\hline C83 & Magnoloside M & 185 & 149 & & & & 169 & 159 & 185 & 208 & & & & 143 & 7 \\
\hline $\mathrm{C} 79$ & Magnoloside G & 163 & 152 & & & & 180 & 155 & 172 & 177 & & & & 164 & 7 \\
\hline $\mathrm{C} 76$ & Magnoloside E & 194 & 153 & & & & 183 & 173 & 184 & 211 & & & & 149 & 7 \\
\hline C75 & Magnoloside D & 187 & 154 & & & & 183 & 172 & 187 & 211 & & & & 159 & 7 \\
\hline C74 & Magnoloside A & 178 & 161 & & & & 165 & 171 & 189 & 185 & & & & 148 & 7 \\
\hline C53 & Lariciresinol & & 114 & 154 & & & 135 & 147 & & 156 & 159 & & 131 & & 7 \\
\hline $\mathrm{C} 48$ & Magnolignan $\mathrm{H}$ & 152 & 120 & & & & 133 & 147 & 165 & 194 & & & 124 & & 7 \\
\hline C46 & Houpulin K & 166 & 115 & & & & 169 & 150 & 164 & 189 & & & 111 & & 7 \\
\hline C41 & Magnolignan F & 158 & 132 & & & & 170 & 149 & & 204 & & & 142 & 135 & 7 \\
\hline C169 & Syringaresinol 4'-O- $\beta$-D-glucopyranoside & & 112 & & & & 152 & 145 & 163 & 178 & & & 134 & & 6 \\
\hline C123 & Isorhamnetin-3-O- $\beta$-D-glucoside & & 117 & & 152 & & 143 & & & 159 & 162 & & 119 & & 6 \\
\hline C121 & Quercitrin & & 121 & & 153 & & 135 & & & 158 & 161 & & 127 & & 6 \\
\hline C94 & $\begin{array}{l}\text { 1, 1'-dibenzene-6', 8', 9'-trihydroxy-3-allyl-4- } \\
\text { O-B-D-qlucopyranoside }\end{array}$ & & 130 & & & & 149 & 148 & & 172 & & 157 & 151 & & 6 \\
\hline C86 & Acteoside & & 149 & & & & 182 & 162 & 181 & 194 & & & & 155 & 6 \\
\hline $\mathrm{C} 80$ & Magnoloside $\mathrm{H}$ & 192 & 148 & & & & 197 & & 191 & 239 & & & & 170 & 6 \\
\hline C55 & Lirioresinol A & & 111 & & & & 142 & 147 & & 164 & 156 & & 140 & & 6 \\
\hline C54 & Syringaresinol & & 116 & & & & 143 & 146 & & 162 & 149 & & 148 & & 6 \\
\hline C47 & Houpulin L & 155 & 135 & & & & 154 & 157 & & 181 & & & 122 & & 6 \\
\hline $\mathrm{C} 43$ & Houpulin B & 160 & 128 & & & & 156 & 154 & & 176 & & & 142 & & 6 \\
\hline C32 & Bornyl magnolol & & 115 & & & 152 & 138 & & & 148 & 154 & & 132 & & 6 \\
\hline C30 & Piperityl honokiol & & 119 & & & 150 & 141 & & & 153 & 135 & & 137 & & 6 \\
\hline $\mathrm{C} 29$ & Piperityl magnolol & & 122 & & 148 & & 136 & & & 152 & 156 & & 138 & & 6 \\
\hline
\end{tabular}




\section{Go Term}

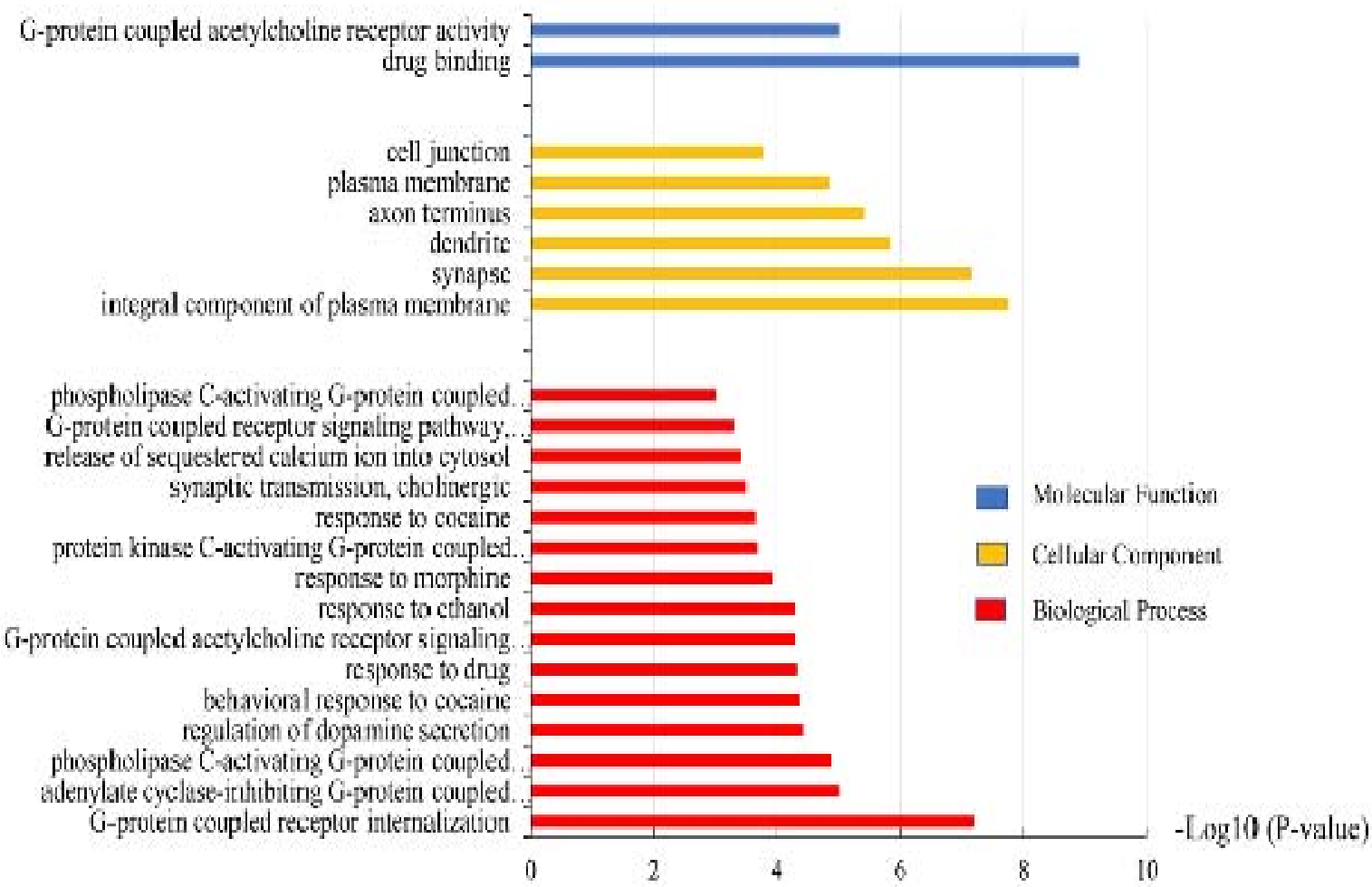

Figure 3: The analysis of GO for target genes.

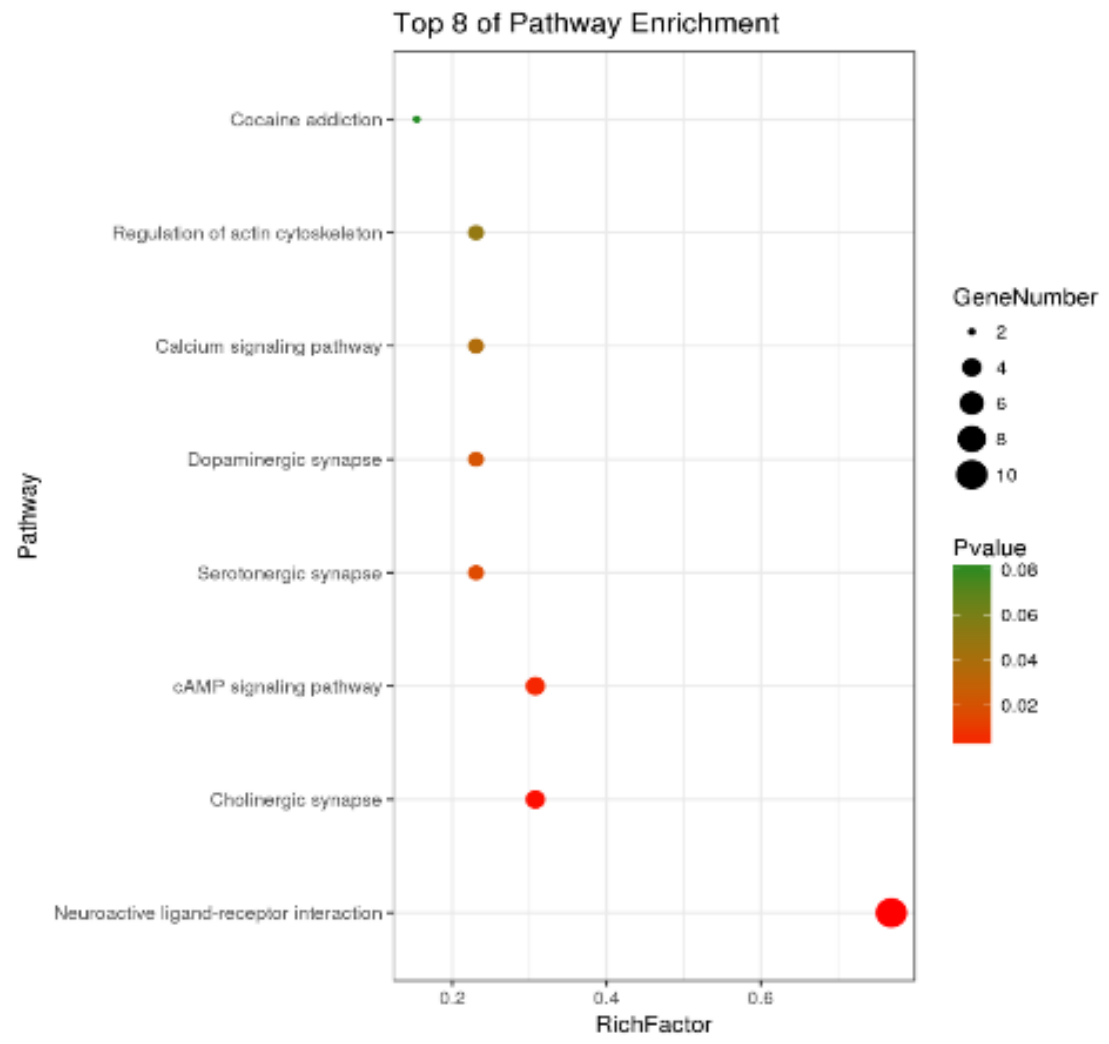

Figure 4: Bubble chart of 8 signaling pathways linked to the anti-FD of $\mathrm{Hou} P \mathrm{Po}$ 
involved in the treating of FD by Hou Po could be "Neuroactive ligand-receptor interaction pathway", which has 10 target proteins. Hou Po has been used for thousands of years, with very little reported side effects. Therefore, the bioactive components of Hou Po could be candidates for development of new drugs against FD.

\section{CONCLUSION}

Molecular docking and network pharmacology have been successfully used to screen for bioactive anti-FD compounds in Hou Po. A total of 31 key bioactive compounds have been identified and selected. Gene enrichment analysis has also revealed the mechanism involved in the anti-FD effect of Hou Po. These findings are beneficial for generating new anti-FD drugs.

\section{DECLARATIONS}

\section{Acknowledgement}

This study was supported by the Fund of Project of Inheritance Studio of National Famous Experts of State Administration of TCM (no. [2019] 41), Scientific Research Innovation Team Construction in Sichuan Provincial University (no. 18TD0017), "XingLin Scholars" Research Promotion Plan of Chengdu University of TCM (no. XGZX2009).

\section{Conflict of interest}

No conflicts of interest are associated with this work.

\section{Contribution of authors}

We declare that this work was performed by the authors named in this manuscript, and all liabilities on claims relating to the content of this article will be borne by them. Yingfang Wei, Fei long and Guanghua Lv conceived and designed the study. Meng Yang, Yusha Bai, and Longjing Wang collected the data. Jun He did the detailed experiments and wrote the manuscript. Yunbin Jiang modified the manuscript. All authors read and approved the manuscript for publication.

\section{Open Access}

This is an Open Access article that uses a funding model which does not charge readers or their institutions for access and distributed under the terms of the Creative Commons Attribution License (http://creativecommons.org/licenses/by/
4.0) and the Budapest Open Access Initiative (http://www.budapestopenaccessinitiative.org/rea d), which permit unrestricted use, distribution, and reproduction in any medium, provided the original work is properly credited.

\section{REFERENCES}

1. Oikawa $T$, Ito $G$, Hoshino $T$, Koyama $H$, Hanawa $T$. Hangekobokuto (Banxia-Houpo-tang), a Kampo Medicine that Treats Functional Dyspepsia. Evid Based Complement Alternat 2009; 6(3): 375-383.

2. Zhao MQ, Chen $Y$, Wang $C$, Xiao $W$, Chen S, Zhang S, Yang $L, L i Y$. Systems Pharmacology Dissection of Multi-Scale Mechanisms of Action of Huo-Xiang-ZhengQi Formula for the Treatment of Gastrointestinal Diseases. Front Pharmacol 2019; 11(9): 1448.

3. Luo $H, W u H, Y u X$, Zhang $X, L u Y$, Fan J, Tang L, Wang $Z$. A review of the phytochemistry and pharmacological activities of Magnoliae officinalis cortex. J Ethnopharmacol 2019; 236: 412-442.

4. Zhang J, Chen Z, Huang $X$, Shi $W$, Zhang $R$, Chen $M$, Huang $H$, Wu L. Insights on the Multifunctional Activities of Magnolol. Biomed Res Int 2019; 23: 1847130.

5. Kim HJ, Han T, Kim YT, So I, Kim BJ. Magnolia Officinalis Bark Extract Induces Depolarization of Pacemaker Potentials Through M2 and M3 Muscarinic Receptors in Cultured Murine Small Intestine Interstitial Cells of Cajal. Cell Physiol Biochem 2017; 43(5): 17901802.

6. Cosconati S, Forli S, Perryman AL, Harris R, Goodsell DS, Olson AJ. Virtual Screening with AutoDock: Theory and Practice. Expert Opin Drug Discov 2010; 5(6): 597607.

7. Peng $W$, Shen $H$, Lin B, Han P, Li C, Zhang $Q, Y e ~ B$, Rahman $K$, Xin $H$, Qin $L$, et al. Docking study and antiosteoporosis effects of a dibenzylbutane lignan isolated from Litsea cubeba targeting Cathepsin $\mathrm{K}$ and MEK1. Med Chem Res 2018; 27(9): 2062-2070.

8. Tang H, He S, Zhang $X$, Luo S, Zhang B, Duan X, Zhang $Z$, Wang W, Wang $Y$, Sun Y. A Network Pharmacology Approach to Uncover the Pharmacological Mechanism of XuanHuSuo Powder on Osteoarthritis. Evid Based Complement Alternat Med 2016; 2016:3246946.

9. Jing WG, Du J, Wang JG, Sun XB, Lan QS. Review on Chemical Constituents of Magnoliae Officinalis Cortex. Moder Chin Med 2018; 20(6): 764-774.

10. Zhang J, Zhang Q, Chen $X$, Liu Y, Xue J, Dahan A, Zhang $H$, Chai $Y$. Revealing Synergistic Mechanism of Multiple Components in Gandi Capsule for Diabetic Nephropathy Therapeutics by Network Pharmacology. Evid Based Complement Alternat Med 2018; 2018: 6503126.

11. Zhang $Q$, Li RL, Peng $W$, Gao $Y X, W u$ CJ, Pu XF. In silico screening of anti-inflammatory constituents with good drug-like properties from twigs of Cinnamomum cassia based on molecular docking and network pharmacology. Trop J Pharm 2019;18: 2125-2131.

Trop J Pharm Res, August 2020; 19(8): 1729 
12. Huang da W, Sherman BT, Lempicki RA. Systematic and integrative analysis of large gene lists using DAVID bioinformatics resources. Nat Protoc 2009; 4(1): 44-57.

13. Jack J, Van den Houte $K$, Carbone F. The Unfulfilled Promise of Prokinetics for Functional Dyspepsia/Postprandial Distress Syndrome. Am J Gastroenterol 2019; 2(114):204-206.

14. Mahadeva S, Ford AC. Clinical and epidemiological differences in functional dyspepsia between the East and the West. Neurogastroenterol Motil 2016; 28(2):167-241.

15. Hidekazu S, Toshihiro N, Toshifumi $H$. Therapeutic strategies for functional dyspepsia and the introduction of the Rome III classification. J Gastroentero 2006; 6(41): 513-523.

16. Shakhatreh $M$, Jehangir A, Malik Z, Parkman HP. Metoclopramide for the treatment of diabetic gastroparesis. Expert Rev Gastroenterol Hepatol 2019; 13(8): 711-721.

17. Lai CH, Yeh YC, Chen YY. Metoclopramide as a prokinetic agent for diabetic gastroparesis: revisiting the risk of Parkinsonism. Ther Adv Drug Saf 2019; 20(10): 2042098619854007.

18. Hondeghem LM. Domperidone: limited benefits with significant risk for sudden cardiac death. J Cardiovasc Pharmacol 2013; 61(3): 218-243.
19. Kim HW, Li H, Kim HS, Shin SE, Jung WK, Han ET, Hong SH, Choi IW, Park WS. Cisapride, a selective serotonin 5-HT4-receptor agonist, inhibits voltagedependent $\mathrm{K}(+)$ channels in rabbit coronary arterial smooth muscle cells. Biochem Biophys Res Commun 2016; 478(3): 1423-1431.

20. Du Y, Su T, Song X, Gao J, Zou D, Zuo C, Xie W, Wang $B$, Zhang $Z, X u$ J. Efficacy and safety of cinitapride in the treatment of mild to moderate postprandial distress syndrome-predominant functional dyspepsia. J Clin Gastroenterol 2014; 48(4): 328-335.

21. López-Rubalcava $C$, Piña-Medina $B$, Estrada-Reyes $R$, Heinze G, Martínez-Vázquez M. Anxiolytic-like actions of the hexane extract from leaves of Annona cherimolia in two anxiety paradigms: possible involvement of the GABA/benzodiazepine receptor complex. Life Sci, 2006; 78(7): 730-737.

22. Xue $Z$, Wu $C$, Wei J, Xian $M$, Wang $T$, Yang $B$, Chen $M$. An orally administered magnoloside $A$ ameliorates functional dyspepsia by modulating brain-gut peptides and gut microbiota. Life Sci 2019;15(233): 116749.

23. Kim JE, Lee MR, Park JJ, Choi JY, Song BR, Son HJ, Choi YW, Kim KM, Hong JT, Hwang DY. Quercetin promotes gastrointestinal motility and mucin secretion in loperamide-induced constipation of $S D$ rats through regulation of the mAChRs downstream signal, Pharm Biol 2018; 56(1): 309-317. 